\title{
The Research on Nash Negotiation Model of Risk Sharing for ERP Project Implementation
}

\author{
Zongqian Zhu, Mei Zhang, Xiaodou Liang, Yan Huang \\ School of Economics \& Management, Xi'an University of Technology, Xi'an, China. \\ Email: gyzzq0229@yahoo.com.cn,gy_zhangmei@126.com, leungjiayu@163.com
}

Received January 29 ${ }^{\text {th }}, 2013$; revised March $8^{\text {th }}, 2013$; accepted March $15^{\text {th }}, 2013$

\begin{abstract}
In the ERP project implementation, it is an important mean to control the implementing risk effectively that distinguishing and fulfilling ERP project risk sharing responsibilities between the enterprise and the partners. Starting from the three-stage of decision and three-layer structure of main participants, this paper constructs risk sharing index system and constructs model to obtain risk sharing initial proportion for ERP project using AHP, then using the balance of responsibility, right and benefit to convert risk allocation to profits allocation problem. Starting from the goal of maximizing the overall satisfaction of all partners, the paper constructs the second stage model based on Nash negotiation.
\end{abstract}

Keywords: ERP Project; Sharing Model; Nash Negotiation; AHP

\section{Introduction}

Because ERP project is a complex enterprise information engineering which includes multi-stage, multi-activity and multi-partner, so many enterprises and scholars focus on risk controlling [1]. As an enterprise level application system, its application technology become more and more complex, and the scale of the system is also larger, the right external partners must be introduced, and by using all kinds of resources and expertise of the external partners, many kinds of ERP implementation risks will be reduced. But if there is no clear risk sharing responsibility partition between partners after introducing the external partners, the original risk may not be reduced, on the contrary, new cooperation risk will appear, which will damage the interests of all partners ultimately. Therefore, only by constructing reasonable risk sharing model and using the model to express the responsibilities and rights between partners clearly and to mobilize all partners' positivity and initiative of risk control, finally the purpose of risk control will be achieved.

At present, researches on risk sharing are mainly focused on the field of engineering project cooperation, supply chain cooperation, finance and risk investment cooperation et al. For example, for PPP project Yongjian Ke, Albert [2] et al. distributed the identified 14 species risk into government and private sector by using the Delphi method; Yelin Xu, Albert [3] et al. took the risk bearing ability as the core factor to establish the risk sharing model with the fuzzy comprehensive evaluation method for PPP project; Yuelong Fu [4] et al. discussed risk sharing problem of subcontract in supply chain, and proposed a general analysis formation of subcontract risk sharing and risk sharing model based on principal-agent theory; as to sharing risk for government and project sponsors about infrastructure projects financing risk, Xiaojun Fan [5] et al. constructed decision model of risk sharing proportion from view of influencing project cost and influencing project profits. ERP implementation process has a typical nature of multi-partners, the author [6] once conducted research on key factors which influence the ERP project risk sharing through the empirical study and put forward the risk allocation proportion model based on fuzzy analytic hierarchy process.

Through analyzing, we find that prior studies still have some deficiencies: 1) Only pursuing rationality and objectivity of allocation results, but not paying enough attention to whether the partners are satisfied with the results and are willing to accept them, so the responsibility of risk sharing can't be put into effect easily; 2) It did not take responsibility, right and profit into consideration in risk allocation, and lacked attention on benefits driven of risk sharing; 3) The target of risk allocation failed to reflect direct requirements of risk control.

Therefore, other ways are needed to be further explored so that the results of risk allocation can be more reasonable and accepted by partners easily.

Nash negotiation model is a good research method in interest distribution, it has made some achievements. For example, Weidong Feng [7] had adopted Nash negotiation model to determine dynamic alliance partners enterprise profits allocation proportion. Wu Lang [8] put for- 
ward the method of two-stage interest distribution method based on Nash negotiation for dynamic logistics alliance in output share mode. However, related literature on Nash negotiation model for ERP project risk allocation has not appeared yet. In addition, with the lacking of a reasonable referenced standard, the result of using Nash negotiation is often optional, which can influence the rationality of conclusion.

\section{Idea of ERP Project Implementation Risk Sharing Modeling}

As to existing problems in the prior research, the basic thinking of building the risk sharing model is put forward (shown in Figure 1).

\subsection{The Model Construction of Risk Sharing Based on the Idea of Two-Stage Optimization}

The risk sharing proportion reflects responsibility proportion of risk control and bearing proportion of risk results, Therefore, the construction of ERP project risk sharing model should not only focus on total goal of effective risk control, but also should reflect the willingness of each partner, which can make the partners have a higher identification and satisfaction and make the decision process embody democracy and consultation fully. Then real responsibility risk allocation will be accomplished explicitly, the process will be open and the risk control can be put into practical. For this, this paper will achieve the optimization goal of risk sharing by constructing twostage model below.

\subsection{AHP Model Construction of Risk Sharing Based on the Goal of Risk Control}

Starting from target of risk control, based on risk allocation decisions to consider the main influence factors, according to the principle of "the influence degree of risk control decide the proportion of the risk", with the role of all levels weights of analytic hierarchy process, we calculate the total influence degree of all the partners of risk control which is the degree of importance of the partner in the risk control, and transfer them to the partner risk proportion and get the initial sharing proportion plan of risk allocation.

\subsection{Nash Negotiation Model Construction Based on Maximum Satisfaction}

According to the balance principle of responsibility, right and profit, the ERP project risk allocation problem is not only a risk liability distribution and practicable problem, but also a profit allocation problem of practical equivalence of risk liability, so the risk allocation problem can

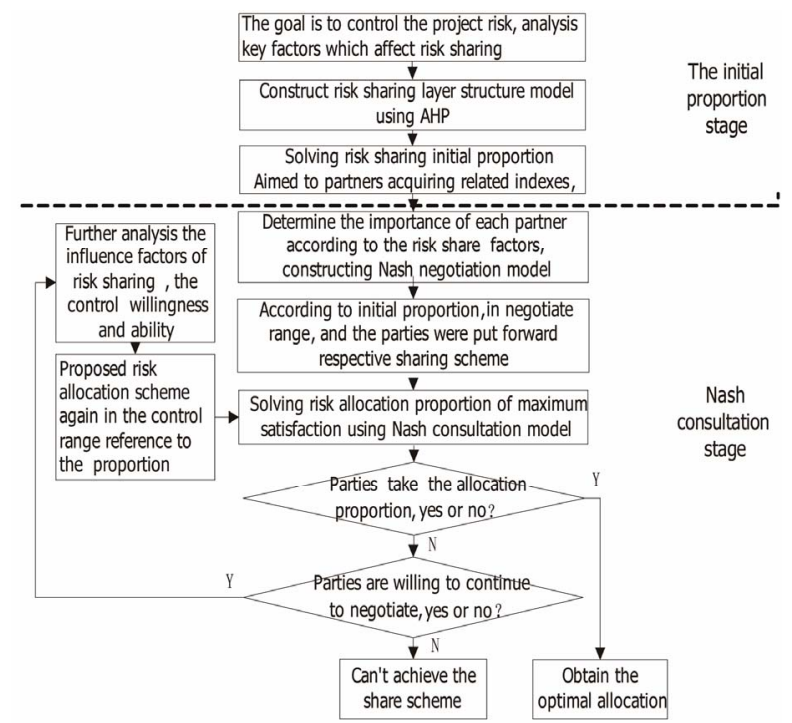

Figure 1. The basic thought of risk sharing model structure of ERP project.

be converted into interest distribution problem when considering risk sharing synchronously, which can be settled by Nash.

Therefore, the second stage starts from the initial plan of the first stage, targets with the overall satisfaction of each partner, and then constructs Nash negotiation model and makes full use of democratic consultation mechanism. All partners can refer to the calculation results for decision-making, if they accept, then the solution will be the optimal share scheme. If there is one or more partners does not accept the scheme but will be willing to continue to negotiate, then each partner can again give consultation proportion in the condition that the whole satisfaction will not reduce according to the consultation proportion, recalculating the allocation proportion. The negotiation process has been continuing till all partners can accept the distribution proportion. Therefore, through Nash negotiation model, we can obtain risk allocation scheme with the highest overall satisfaction.

\section{The Determination of ERP Project Risk Sharing Initial Proportion Based on the AHP}

\subsection{The Influence Factors Analysis of ERP Project Implementation Risk Sharing}

To control project risk is the core goal of the risk allocation. For the targets of risk control and features of ERP project implementation, starting from the decision thinking mode "Looking before and after, considering the reality," the main influence factors can be divided into risk bearing intention, risk control ability and risk bearing ability. Meanwhile, considering ERP project implementation usually appear in the form of organization, taking 
the team as the main participants and using the project manager responsibility system. So according to different role of each participant playing in the risk control, the main participants are divided into three levels: enterprise, implementation team and project manager. The enterprise mainly provides the various related resources for risk management and control; implementation team ensures all kinds of effective methods and technical support for risk management and control; managers need to have management skills for risk management and control, which are of the three levels of main body structure of risk control. Starting From two dimensions of three-layer structure of main participants and three-phase risk control decision-making process, the risk sharing influencing factors analysis matrix of ERP implementation (shown in Table 1) can be set up.

\subsection{Model Construction and Solution of Risks Sharing of ERP Project Implementation}

According to the independence and quantifiable of index system, based on advice from interview with senior experts, we modified and refined indexes, finally obtained a set of risk sharing hierarchy model (shown in Figure 2).

1) Model Construction

This model includes four sections: the goal layer, criterion layer, sub-criteria layer and scheme layer.

The first layer is the goal layer, which is the optimal risk allocation proportion for controlling risk $R_{x}$, which means to the purpose of solving problem.

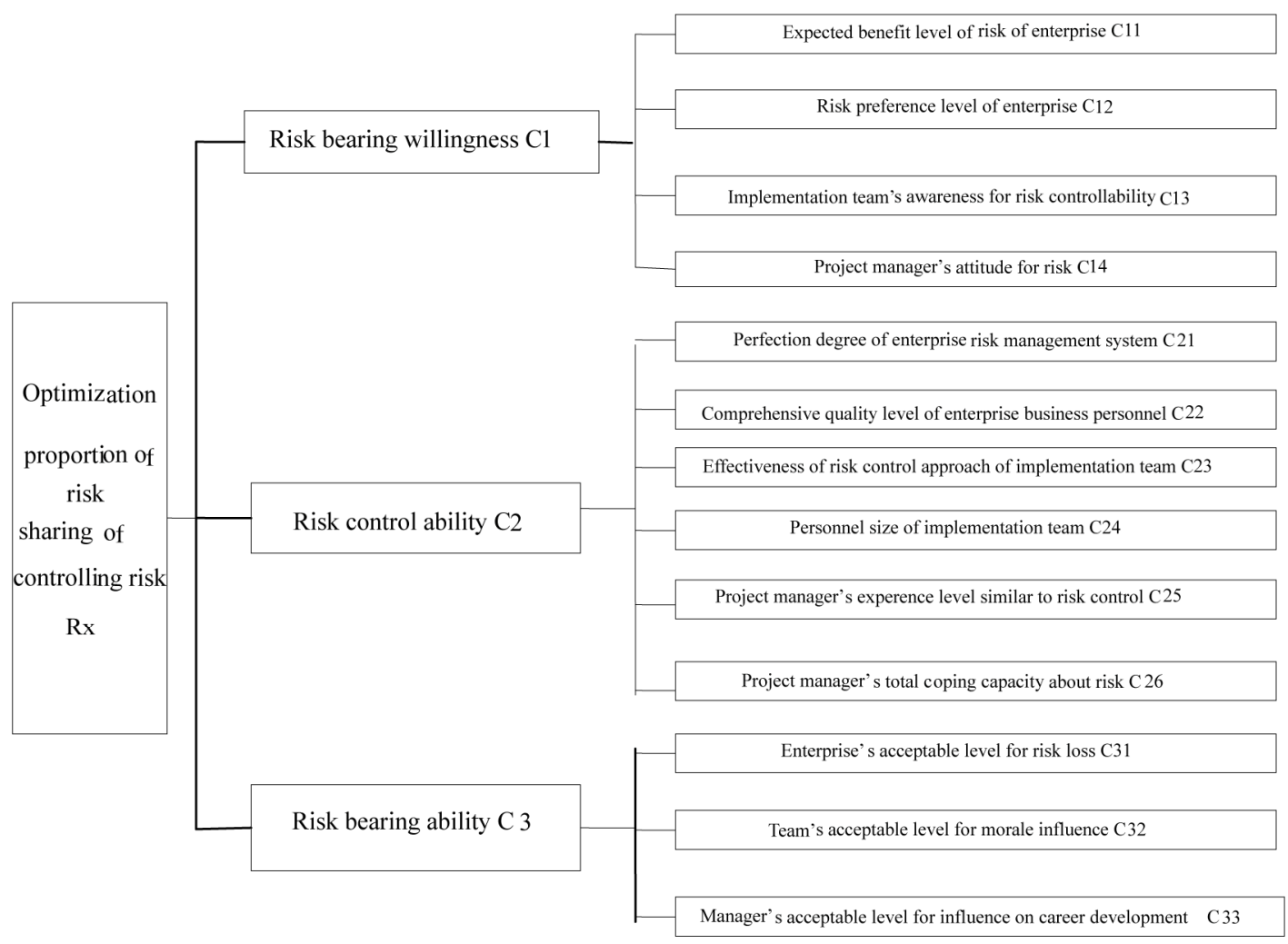

Figure 2. Hierarchical structure model of risk sharing in ERP project.

Table 1. Influencing factor analysis matrix of ERP project risk allocation.

\begin{tabular}{|c|c|c|c|}
\hline $\begin{array}{l}\text { Decision stage } \\
\text { body }\end{array}$ & Risk bear willing & Risk control ability & Risk bear ability \\
\hline $\begin{array}{l}\text { Enterprise } \\
\text { organization }\end{array}$ & $\begin{array}{l}\text { Take risks' expected returns; The risk } \\
\text { preference of enterprise organization }\end{array}$ & $\begin{array}{l}\text { The perfect degree of risk management } \\
\text { system; The comprehensive quality of } \\
\text { business personnel }\end{array}$ & The acceptable level of risk of loss \\
\hline Implementation team & Understanding to the risk control & $\begin{array}{l}\text { The means, method and measure of risk } \\
\text { control; Implementation team personnel } \\
\text { scale }\end{array}$ & $\begin{array}{l}\text { The acceptable level for team morale, } \\
\text { stability, and shadow }\end{array}$ \\
\hline Project manager & The manager's attitude to risk & $\begin{array}{l}\text { Similar risk control experience; Risk } \\
\text { comprehensive coping ability }\end{array}$ & $\begin{array}{c}\text { The acceptable level of career development } \\
\text { influence }\end{array}$ \\
\hline
\end{tabular}


The second layer is criterion layer, that is, determining the main index of risk sharing, including risk bearing intention, risk control ability and risk bearing ability. It is expressed by $C_{i}, i=1,2,3$ the corresponding weights set is $W_{i}=\left(W_{1}, W_{2}, W_{3}\right)$. Where $W_{i}$ means relative importance level of main index $C_{i}$ among controlling risk $R_{x}$.

The third layer is sub-criteria layer, which determines secondary index layer of risk sharing proportion expressed by $C_{i j}$, the corresponding weights sets is $W_{i j}=\left(W_{i 1}, W_{i 2}, \cdots, W_{i j}\right)(1 \leq j \leq 6)$, where $W_{i j}$ means the relative importance level of secondary index $C_{i j}$ to the main index $C_{i}$.

The fourth layer is scheme layer, that is, the layer of project risk sharing scheme, that is, potential risk bearing partner of project implementation (project implementation partners), expressed by $P, P=\left(P_{1}, P_{2}, \cdots, P_{4}\right)$, the corresponding weights sets is $X_{i j n}=\left(X_{i j 1}, X_{i j 2}, \cdots, X_{i j n}\right)$, where $X_{i j n}$ means the relative influence level of the partner $\mathrm{n}$ for the risk sharing factors $C_{i j}$.

2) Parameters Determination

The parameters of the model are mainly the weight of the criterion layer and the sub-criteria layer. We can get the corresponding weights according to pairwise comparisons of two indexes in the analytical hierarchy process.

Through surveying 10 typical ERP implementation enterprises in China and making interview purposefully with ERP implementation project manager, informatization manager and ERP implementation consulting senior experts participated in ERP implementation et al., they gave the estimate matrix, then we calculated the weight using the arithmetic average method, the specific score and the weight are shown in Table 2.

Similarly, through the same grading and calculation method used in first-class index, the weights of secondclass index are as follows:

$$
\begin{aligned}
& W_{1 i}=(0.301,0.278,0.243,0.178) \\
& W_{2 i}=(0.124,0.138,0.172,0.096,0.214,0.256) \\
& W_{3 i}=(0.378,0.354,0.268)
\end{aligned}
$$

3) Model Solution

After determining the weight of each layer, the key to solve the model lies in how to obtain the relative importance value of each partner for the sub-criteria layer index, namely the measuring variables of the model. For one index of sub-criteria layer, by comparing the corresponding weights $X_{i j k}$ of partner k to this index, then we can determine partner $k$ 's risk bearing ratio according to Formula (1).

$$
W_{k}=\sum_{i j} w_{i} w_{i j} x_{i j k}
$$

\section{Determination of ERP Project Risk Allocation Optimization Proportion Based on Nash Negotiation}

The ERP project is a complex engineering which has more participants in implementation process. It's good to improve all partners' satisfaction to adopt the negotiation way to determine the risk allocation scheme. Therefore, on the basis of risk allocation initial proportion, further to determine risk sharing proportion scheme with the largest overall satisfaction through the democratic negotiation.

\subsection{Model Construction}

For more negotiation problem, Nash had put forward negotiations model of multi-people negotiation countermeasure [9]. Let's assume n partners participating in ERP project implementation risk sharing, each partner raises a risks bearing scheme with other partners according to the level of his role played in the implementation and risk allocation principle.

Supposing partner $i$ puts forward a risk allocation scheme, that is $q_{i}=\left(q_{1 i}, q_{2 i}, \cdots, q_{n i}\right)^{\mathrm{T}}, i=1,2, \cdots, n$. where $q_{i j}$ means the partner $j$ 's risks allocation proportion presented by the partner i in risk sharing coordinate projects, $0<q_{i j}<1$. and $\sum_{i=1}^{n} q_{i j}=1$. So $n$ partners will put forward $n$ risk sharing coordinate projects, which will $n * n$ order matrix: $q=\left[\begin{array}{cccc}q_{11} & q_{12} & \cdots & q_{1 n} \\ q_{21} & q_{22} & \cdots & q_{2 n} \\ \vdots & \vdots & \ddots & \vdots \\ q_{n 1} & q_{n 2} & \cdots & q_{n n}\end{array}\right]$

Supposing highest expected risk sharing ratio of partner $i$ is $q^{+}(i), q^{+}(i)=\max _{j=1 \rightarrow n}\left\{q_{j i}\right\}$, so highest potential risk sharing scheme set of ERP implementation partner is $Q^{+}=\left(q^{+}(1), q^{+}(2), \cdots, q^{+}(n)\right)$. But $\sum_{i=1}^{n} q^{+}(i) \geq 1$, it

Table 2. The grades and weight of first-class index.

\begin{tabular}{cccc}
\hline Second development risk & Risk bearing willing $C_{1}$ & Risk control ability $C_{2}$ & Risk bearing ability $C_{3}$ \\
\hline Risk bearing willing $C_{1}$ & 1 & 0.513 & 3.208 \\
Risk control ability $C_{2}$ & 1.949 & 1 & 4.957 \\
Risk bearing ability $C_{3}$ & 0.312 & 0.202 & 0.559 \\
\hline
\end{tabular}


Can't satisfy the constraint conditions of all risk bearing proportion is 1 , so negotiation is needed between all partners. Setting the lowest expected risk share ratio of partner $i$ is $q^{-}(i), q^{-}(i)=\min _{j=1 \rightarrow n}\left\{q_{j i}\right\}$, So ERP implementation partner lowest risk sharing scheme set is

$$
Q^{-}=\left(q^{-}(1), q^{-}(2), \cdots, q^{-}(n)\right)
$$

Supposing $r_{i}$ is the risk bearing proportion of partner $i$. For partner $i$, bearing risk and benefits are symmetrical. So the satisfaction of risk allocation scheme of partner $i$ can be expressed as:

$$
f_{i}=\frac{r_{i}}{q^{+}(i)}
$$

where $r_{i} \geq q^{-}(i), \quad q^{-}(i)$ is the starting point of the negotiations to partner $i$, the lowest satisfaction of partner $i$ is:

$$
f_{i}^{-}=\frac{q^{-}(i)}{q^{+}(i)}
$$

According to Nash negotiate model: Objective function:

$$
\operatorname{Max} Z=\coprod_{i=1}^{n}\left(\frac{r_{i}}{q^{+}(i)}-\frac{q^{-}(i)}{q^{+}(i)}\right)^{w_{i}}
$$

Constraint conditions:

$$
\text { s.t. }\left\{\begin{array}{l}
q^{-}(i) \leq r_{i} \leq q^{+}(i) \\
\sum_{i=1}^{n} r_{i}=1
\end{array}\right.
$$

Using Kuhn-Tucker conditions [25] to solve (4), (5):

$$
r_{i}^{*}=q^{-}(i)+\left(1-\sum_{i=1}^{n} q^{-}(i)\right) \frac{w_{i} q^{+}(i)}{\sum_{i=1}^{n} w_{i} q^{+}(i)}
$$

Formula (6) is the solution to Nash negotiation model based on the satisfaction, $q^{-}(i)$ represents reserved risk ratio of partner $i$, namely the negotiation basis points, $\left(1-\sum_{i=1}^{n} q^{-}(i)\right) \frac{w_{i} q^{+}(i)}{\sum_{i=1}^{n} w_{i} q^{+}(i)}$ represents risk allocation compensation proportion of partner $i$.

\subsection{Determination and Solution of Model Parameters}

1) Determination of Parameters $w_{i}$

The parameter $w_{i}$ reflects the importance level of role which partner $i$ play for controlling some risks in ERP implementation.

In order to construct the Nash negotiation model, it needs to determine the value of the parameter $w_{i}$. Because the degree of each partner's role in risk control can be influenced by its bearing willing, control ability and bearing ability, while the construction of the first-stage model is the index system established on the basis of considering these factors. Therefore, risk allocation proportion $w_{i}$ obtained from the analytic hierarchy process can also reflect the importance level $w_{i}$ of role which all partners play for controlling risks in ERP implementation. Let $i=k$, then $w_{i}=W_{i},(i, k=1,2, \cdots, n)$.

As long as determining the value of $w_{i}$, the next step is to solve the model.

2) Model Solution

After determining the model parameters, each partner needs to put forward their risk sharing scheme in negotiate range according to the risk allocation initial proportion of the first phase, we can get a $n * n$ order risk allocation coordinate projects set.

According to the value of the parameter $w_{i}$ and combining formula (6), we will get the solution of the Nash negotiation model, that is,

$$
R=\left(r_{1}^{*}, r_{2}^{*}, \cdots, r_{n}^{*}\right), \sum_{i=1}^{n} r_{i}^{*}=1, i=1,2,3,4 \text {, 4, where } r_{i}^{*} \text { is }
$$

the risk allocation proportion when partner $i$ has biggest satisfaction.

If the risk allocation proportion is accepted by all partners, that is, we get the final risk allocation proportion. Otherwise, keeping the overall satisfaction nondecreasing, through continuous negotiations the partners put forward risk sharing coordination projects and coming into the next round of Nash negotiations model solution until the partners get risk allocation proportion which all partners are satisfied with.

\section{Conclusion}

The paper explored the best sharing plan by constructing the ERP project implementation risk sharing two-stage model, which provides a new idea for rational sharing of ERP project implementation risks. The two-stage model of risk sharing not only reflects the objective requirements of risk sharing, but also the characteristic of democracy and friendly negotiation, it has strong maneuverability and its results will also be accepted by each partner easily. In the future, research need to combine risk sharing problems with each partner contract formulation process to provide legal safe guard for the effective implementation project risk sharing results.

\section{Acknowledgements}

This work is supported by the National Natural Science Founds Project (70972052); the Natural Science Foundation of Shaanxi Province (2009JM9005); the Department of Education Science Research Project Program of Shaanxi Province (09JK159); the Department of Education Science Research Project Program of Shaanxi Province (11JK0189). 


\section{REFERENCES}

[1] D. Aloini, R. Dulmin and V. Mininno, "Risk Management in ERP Project Introduction: Review of the Literature," Information \& Management, Vol. 44, 2007, pp. 547-567.

[2] Y. J. Ke, S. Q. Wang, A. P. C. Chan and P. T. I. Lam, "Preferred Risk Allocation in China's Public-Private Partnership (PPP) Projects,” International Journal of Project Management, Vol. 28, No. 5, 2010, pp. 482-492. doi:10.1016/j.ijproman.2009.08.007

[3] Y. L. Xu, A. P. C. Chan and J. F. Y. Yeung, "Developing a Risk Assessment Model for PPP Projects in China-A Fuzzy Synthetic Evaluation Approach,” Journal of Construction Engeering and Management, Vol. 19, No. 7, 2010, pp. 929-943.

[4] Y. L. Fu, D. S. Xiao and L. H. Guo, "The Research on Risk Sharing of Subcontract in Supply Chain,” Systems Engineering, Vol. 2, 2005, pp. 123-126.
[5] X. J. Fan, Y. Zhao and G. Y. Zhong, "Study on Allocation Proportion of Infrastructure Project Financing Risk," Journal of Industrial Engineering and Engineering Management, Vol. 21, No. 1, 2007, pp. 98-101.

[6] Z. Q. Zhu, Y. X. Li and A. Luo, “An Empirical Study on Influencing Factors of Risk Sharing in ERP Project,” Industrial Engineering and Management, Vol. 15, No. 2, 2010, pp. 98-102.

[7] W. D. Feng and J. Chen, “The Determination of Partners' Benefit Allocation Proportion in Virtual Enterprise,” Systems Engineering Theory and Practice, Vol. 4, 2004, pp. 45-49.

[8] L. Wu, "Interest Distribution Method of Dynamic Logistics Alliance in Output Share Mode," Systems Engineering, Vol. 27, No. 5, 2009, pp. 25-30.

[9] J. F. Nash, “The Bargaining Problem,” Econometrica, Vol. 18, No. 2, 1950, pp. 155-162. doi:10.2307/1907266 